\title{
Le monde en visite au cabinet médical
}

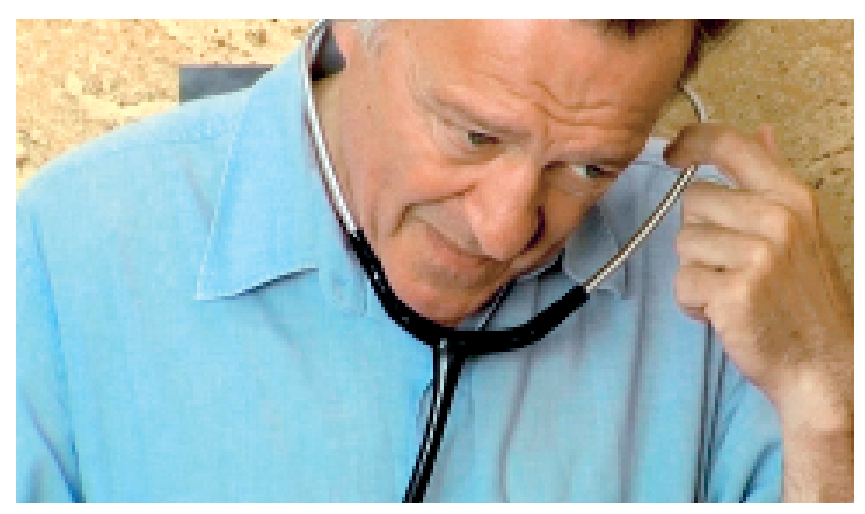

Luc Perino: médecin corps et âme.

\section{Au plus près du corps c'est l'âme qui surgit \\ (du générique du film «La consultation»)}

- La consultation. Un film d'Hélène de Crécy. France, 2006. Durée 91 minutes. Le film débutera en Suisse romande en mars 2007 et en septembre 2007 en Suisse alémanique. Autres informations sur le site internet www.xenixfilm.ch.
C'est la mort que l'on voit d'abord. En prélude du film «La consultation» qui documente le quotidien du généraliste français Luc Perino, la caméra accompagne le médecin auprès d'un mourant. C'est d'emblée le point qui rassemble tous les fils de l'histoire, les protagonistes du film comme les spectateurs.

Retour en arrière, dans la vie où l'on voit le patient «tout neuf», en tant que nourrisson d'une dizaine de jours qui, selon sa mère, souffre de crampes à l'estomac et de constipation. Entre ces deux extrêmes s'ouvre le microcosme du cabinet sous tous ses angles. On voit une fumeuse de 21 ans avec les signes d'une bronchite chronique et souffrante de sinusite. Le bénéficiaire de l'aide sociale qui n'a plus confiance en lui à cause du médicament ordonné. La femme aux attaques de panique. L'homme âgé dont la prostate, à la palpation, s'avère suspecte. La jeune femme asiatique et son ami qui lui traduit la conversation, consultant pour un avortement. La patiente au torticolis. L'alcoolique. La mère désespérée d'un patient schizophrène. L'employé d'un centre d'appels téléphoniques qui ne supporte plus son job. La dame qui vient pour faire son «shopping» de médicaments. La femme très âgée qui présente le soupçon d'une hernie étranglée.

C'est donc le quotidien du cabinet de praticien, comme on le voit si souvent en tant que médecin de premier recours. Qu'est-ce qui peut encore être passionnant dans la vision de ce quo- tidien filmé, tout de discrétion et d'effacement? La caméra reste la plupart du temps à une distance respectueuse. Les longs moments statiques donnent un rythme paisible, souligné par la musique, en somme exactement le contraire de ce qui se passe dans la série télévisée «Urgences» qui recourt à tous les moyens techniques pour mettre en scène un rythme d'enfer.

L'auteur, Hélène de Crécy, crée de cette manière les conditions d'un regard sur l'essentiel: le patient, le médecin et tout ce qui se joue entre eux. Une manière de filmer la règle méditative qui veut qu'on atteigne le calme complet pour voir vraiment ce qui se passe.

Le film peut être accueilli de manières très diverses. On est confronté tout d'abord à une personnalité de grande expérience, qui jouit d'une profonde connaissance de l'homme et traite ses patients avec empathie, engagement et une pointe d'humour mélancolique. Il est conscient de ne pas toujours mener très correctement les conversations au cabinet, selon l'enseignement reçu.

«La consultation» est aussi un hommage à la profession, bientôt dépassée aujourd'hui, d'omnipraticien à l'activité d'une incroyable envergure. C'est une qualité du film d'en rendre conscient. Des aléas les plus complexes sur le plan psychosocial au tableau clinique le plus diffus, en passant par la pose d'un diagnostic traumatologique des plus clairs, on attend du généraliste de faire «ce qui est juste» au vieillard comme au nourrisson, au sans-abri comme à l'entrepreneur. Une tâche intense et passionnante, parfois frustrante et démoralisante.

Enfin, le film comporte bien sûr une dimension d'analyse de société. Les patients, qui apparaissent aussi bien comme archétypes qu'en tant qu'individus, introduisent «le monde entier» au cabinet médical. Un monde fait de brisures et de contrastes dont les souffrants s'accommodent souvent fort mal. Ce n'est pas un phénomène nouveau: Thérèse d'Avila avait déjà comparé la vie à une «mauvaise nuit dans une sale auberge». Cela dit, les temps ont changé, le monde est aujourd'hui au «Prozac»!

Bruno Kesseli 